\title{
Ethical and existential aspects of lifestyle changes
}

Jan Arlebrink ${ }^{1,2}$

\begin{abstract}
Background Many people change their lifestyle and such changes can be either voluntary or involuntary. Often, some sort of crisis forces people to change their lifestyles. Therefore, the difficult existential questions become relevant to those who have been forced to change their lifestyle.

Methods This paper will explore different kinds of lifestyle changes within an ethical and existential context. The ethical context is constituted by the Danish ethicist K.E. Løgstrup and his thoughts on the basic conditions of life for the human being. The existential context is constituted by questions dealing with the foundations of our existence and which man cannot avoid. Results In the examples given, the patients seldom receive any help to process their existential questions and as a consequence their problems become more severe.

Conclusion It is important to treat every patient as a subject and to take care of not only his or her medical problems but also of the patient's existential questions generated by the medical problems.
\end{abstract}

doi.org/10.29102/clinhp.150012

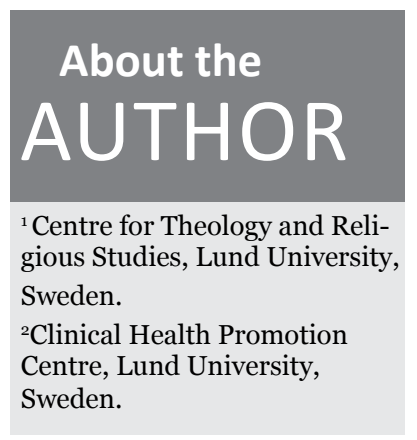

Contact: Jan Arlebrink jan.arlebrink@med.lu.se

\section{Introduction}

There are many reasons for a person to change his or her lifestyle. Lifestyle changes can be voluntary or involuntary and some may be both voluntary and necessary. Examples of such changes can be quitting harmful alcohol, drug, or tobacco misuse, losing weight, or addressing elevated cholesterol levels. Lifestyle changes can also be involuntary, such as those caused by retirement, accidents, separations (divorce, children leaving home), or various diseases (e.g., cancer, chronic diseases). Several important but seldom discussed life style changes will be examined in this paper.

Lifestyle changes involve a variety of factors. Often, crises force individuals to change their lifestyle. As a result of these crises, difficult existential questions become relevant to such individuals and several ethical issues must be considered. For instance, should the person concerned be helped and, if so, how?

\section{Purpose}

The purpose of this paper is to explore several types of lifestyle changes within ethical and existential framework. Such frameworks are applied because lifestyle changes, regardless of their reason and the need for change, require the individual to ask questions about the fundamental nature of life itself. When a person in a crisis situation poses him or herself an existential question about life, the question is also directed towards others. This paper describes how such a question is posed and examines the ethical foundations by which claims may be directed to another person.

\section{The ethical context}

The starting point for the ethical context is based on the Danish ethicist K.E. Løgstrup's thinking about the basic conditions of human life (1). Løgstrup's concept could be summarized in his idea of man as a subject. The concepts which he uses to describe this idea include interdependence (the fact that we are dependent upon each other), the ethical demand, and what he calls the sovereign expressions of life. The latter include trust, veracity and mercy. Another key concept which is also important here is empathy.

The existential context

The existential context is constituted of 
questions about life and its meaning, death, guilt, the meaning of suffering, and our responsibility to ourselves and others. These are unavoidable questions that address the foundations of our existence and which human beings cannot avoid. The questions become fundamental when we are afflicted with a serious illness or are involved in a serious accident and our existence is threatened. Ethical and existential contexts have similarities, and Løgstrup's thoughts (1) apply to both.

\section{Cases}

In the below, four existing cases will be considered, problematised, and reflected upon within the existential and ethical framework.

\section{Voluntary lifestyle changes: high cholesterol levels}

An example of a voluntary but necessary change in lifestyle occurred among twelve men who participated in a study because of high cholesterol levels (2). The purpose of the study was to investigate the process which these men underwent as they attempted to change their lifestyle to reduce their cardiovascular risks. After being informed that they had high risks of developing a serious disease, the men reacted in several ways: All became very worried, some contemplated suicide, and several became anxious that they would die. Som were also in denial, and some attempted to forget the matter. Others began to fear that they would have a heart attack at any moment.

Sachs (2) suggests that instructions advising people to change their lifestyles or to make decisions that will affect their physical health in a certain way assume a belief in predictable connections between life and the body: Certain actions that promote health should result in certain positive outcomes. Sachs, however, also indicates that some people do not achieve the goals they have established despite carefully following the instructions they have received and, as a result, they experience suffering. Although several of the men conscientiously made an effort to change their lifestyles, their cholesterol levels still remained too high one year later. Many of them became desperate and feared that they would soon die.

\section{Existential aspects}

Many of the men's existential questions were related to their test results, especially for those who did not manage to reduce their cholesterol levels. They posed many questions to themselves (2): Is the life I am being forced to live now really worth living? Why has this happened? Why me? Am I going to die because of this? Why does nothing happen when I do all that I can to change my way of life? The way you live is an important part of your life, and now these men were asking whether the life they were now being forced to live was worth it. For example, cutting out whisky on a Saturday night was not a good way to end the week.

Problematically, these men received no help in processing these questions. Existential questions do not attract attention within health care settings to the extent that they warrant. There are several reasons for this. One decisive reason may be that there are no answers to these questions, and medical professionals may, therefore, be unwilling to talk to the patient about them. They claim that there is no purpose in discussing such questions because they have no answers. Therefore, instead of helping the patient cope, they escape from an experience which they consider to be difficult. The suffering which the patient experiences is, thus, not shared with anyone among the staff, and the patient is left to bear the weight of these questions on his or her own. In the study, several of the men were undergoing a traumatic crisis without receiving any help for the related suffering.

\section{Ethical aspects}

From an ethical point of view, it is necessary to consider the idea of man's interdependent relationship, namely that humans are dependent on each other and share a mutual relationship. This creates an ethical demand that one cares for those with whom one is associated. In keeping with this, one can formulate an ethical demand that we should take care of the person whom we are dealing with. This means that the staff overseeing a patient's care is under an ethical obligation to take care of the patient in more than a technical and medical sense and should, therefore, also alleviate the patient's psychological issues.

Another important concept in this context is mercy. Health care staff practice mercy by caring for patients whose illness originates in psychological distress. However, their care should encompass more than treatment for the physical problems that may arise. For the patient to be able to trust the staff, it is necessary that the patient is regarded as a whole person, and not just as a collection of separate body parts that may have deviated from health. Furthermore, it is also important to consider what Løgstrup terms veracity, meaning telling the truth, as a way of creating trust with the patient.

\section{Health promotional aspects}

To the men in the study, health promotion was important. However, it is not only a matter of physical health promotion. Actions that should promote health did not result in positive outcomes. The men were also mentally affected by the test results. Unfortunately, the patients' 


\section{Research and Best Practice}

existential questions were not addressed within the health care setting.

\section{Voluntary lifestyle changes: in-vitro-fertiliza- tion (IVF)}

Another situation that makes a lifestyle change necessary is when a patient has a strong desire to have a child but is unable to. Many people who desire children do not give up but seek alternatives, such as IVF (3). The chance of becoming pregnant depends upon the age of the woman and lifestyle-related factors. The younger the potential mother is, the more likely it is that she will become pregnant. However, some women who become pregnant have miscarriages, and fewer than half of the couples attempting to have a baby with the help of IVF succeed. When the medical intervention is not successful, these couples are left without resources to cope with the traumatic experience. The authors of the IVF study indicate that the central question is whether and to what extent fertility treatments for obese, people who smoke or use alcohol should be made conditional of a lifestyle change.

\section{Existential aspects}

Clearly, couples whose IVF treatment does not result in a child ask themselves many questions: Why did this happen to us? Why are we not able to have a child like everyone else? What is wrong with us? Are we not good enough to be parents? However, most often, the man and the woman are not perceived as individuals by the medical service. Instead, they are objects for the medical service's efforts from a scientific point of view. When the medical service does not succeed in helping the couple and does not offer support or resources, the couple is often left alone to process all the questions that may have arised in relation to the unsuccessful IVF treatment.

\section{Ethical aspects}

From an ethical point of view, the obligation of health professional to help the couple to process difficult existential questions seems obvious. For example, if the treatment is not successful, the couple must adapt their lifestyle to a reality that they did not choose. From an interdependent viewpoint, there is an ethical demand to take care of the couple. It is also an action of mercy to do so. Among the benefits of this approach is an increased level of trust in the medical profession.

When dealing with a patient, it is necessary to adopt a holistic approach by moving beyond the treatment of physical needs. Ethical dilemmas also comprise the mind, often in a very serious way. You may say, that the foundation for the medical service is mercy, and the staff should show this. When patients are treated as objects, there is a great risk that they will lose trust in the medical profession.

\section{Health promotional aspects}

An important part of recovering is to feel trust. If the staff understands that the couple is in need of other kinds of help beyond the provision of clinical services, they may act more empathically. This may assist the couple in processing what they experience as very tragic.

\section{Involuntary lifestyle changes: traffic accidents} A famous case in Sweden involved a young man of around 30 years old who had been in a traffic accident, which left him paralysed and dependent on a respirator. When he no longer needed treatment and care at the hospital, he wanted to take the respirator home and be treated there instead. However, the question arose of who was to pay for his treatment: the health services or the municipality. Neither would assume the responsibility. The young man ended up in a nursing home surrounded by elderly people.

This man had suffered a lifestyle change that he had never imagined. The case subsequently attracted the attention of the media and suddenly a solution was found so that he was able to go home. Unfortunately, the young man had lost the will to live. However, there was no way he could be legally helped to die in Sweden, so he travelled to an institution in Switzerland that could perform assisted suicide.

\section{Existential aspects}

The young man was given no help to cope with the severe existential problems he encountered after his crash and subsequent paralysis. He constantly questioned why it had happened. Why him? Why was life so unfair? Why was it him who would be connected to a respirator for the rest of his days? These questions had no answers, but they are extremely important for people affected in the way as was the young man. It would have been optimal if the patient had received support in seeking answers to his questions. To the best of our knowledge, the man was given no help in processing the crisis which he had been subjected to.

\section{Ethical aspects}

Everyone who saw the young man could see that he was badly affected. However, there are many cases where people have serious diseases that are not visible. When a person has a tumor disorder, for example, it cannot always be seen that the person is sick. But the sick person may be living with the knowledge that he or she may soon die. Many people with serious diseases may be forced to change their lives. They previously lived in a certain way, but when they fell sick, their lifestyle changed. Some things become less important, while others become more important than they were before. The things that become more important generally concern 


\section{Research and Best Practice}

human relationships and experiences. The things that become less important generally concern work.

\section{Health promotional aspects}

This case shows the importance of regarding the patient as a subject who has severe existential questions to deal with. Even if the patient has not expressed these questions, it is important for the health care staff to understand that human beings with a severe disease or injury react by asking themselves existential questions.

Involuntary lifestyle changes: court-ordered treatment of substance abuse

Another example common in Sweden is the coercive treatment of people with substance abuse, which is a non-voluntary change of lifestyle (4). Because these people are forced into treatment against their will, this generates many existential questions. They generally do not understand why they are being forced into treatment. Alcoholics may argue, for example, that drinking alcohol is permitted in Sweden; yet, they are being forced into treatment against their will. What society wants is for the person abusing substances to change his or her lifestyle, but the person involved may not be interested in doing so. Being forced into a treatment that is involuntary generally entails a major trauma for the person, and he or she may not receive any assistance in coping with this trauma. The authors of the study on coercive treatment indicate that the law must be followed up and that court-ordered treatments should be based on evidencebased methods.

\section{Existential aspects}

There may be several reasons why a person becomes an alcoholic. Many research studies done on Alcohol Use Disorder (AUD) concerns biological, neurochemical, genetical or social factors, but there are possibly other important variables to explain AUD. One such factor may be the person's view of life. An interview study (5) was done to examine the worldviews of AUD patients. The findings showed that most of the 15 patients in the study were, in a way, existentially empty. They could not verbalize any view of life, raising the possibility that this emptiness was replaced by alcohol. Existential emptiness may be one important factor together with other factors to explain AUD (6). Many addicts seem to flee from an emptiness that is often difficult to describe in words. They seem to flee to something that relieves the pain produced by life itself.

\section{Ethical aspects}

Another important aspect is responsibility in the sense that we take responsibility for the other person. People who voluntarily or involuntarily change their lives are very vulnerable in many ways. This is because of what they have experienced and the strains involved in changing their lifestyles.

It is not only important to avoid inflicting physical harm, but also to take steps to avoid mentally harming the patient. We may be mentally damaging another person's life by taking care of the person in a way that is harmful to them.

In the relationship between the care provider and the patient, empathy is an important concept. Most care providers naturally posess the ability to behave in an empathetic way. This empathetic approach may also have an additional positive effect in terms of recovery. In lifestyle changes, the care provider's empathetic approach can bring something of value to the patient, regardless of whether the lifestyle change is voluntary or involuntary. When a doctor takes action in an empathetic approach, the patient feels seen and confirmed (7). This builds up the patient's confidence in the doctor. As a result, any concern or fear in the patient can disappear. However, if the doctor does not treat the patient empathetically, the concern, anxiety or resignation felt by the patient remains.

\section{Health promotional aspects}

Like in the other cases, the care providers and the ways in which they look at the patients or clients are very important to generate positive outcomes. Care providers who are empathetic can provide relief and sometimes generate hope.

\section{Discussion}

Analysis of these and similar cases from existential and ethical aspects is based on a method developed by K.E. Løgstrup (1). It is not the only possible method, but it stimulates the examination of aspects seldom discussed in case analyses.

\section{Patient perspective}

Changes in lifestyle, either voluntary or involuntary, often involve a major change in life for the individual. Something is left behind that was previously experienced as important. The way in which the health service treats the patient may be crucial to how the patient copes with the change.

\section{Clinical perspective}

The changes of lifestyle, such as the changes described in this article, may often lead to a personal trauma for the person. Therefore, it is important for the staff within the health service to place attention on the consequences that may arise when a patient voluntary or involuntary is going through a lifestyle change. Patients do not always 


\section{Research and Best Practice}

verbally express their feelings, reactions and thoughts about the new lives which they are faced with. Also, the existential questions of patients may remain unexpressed. Therefore, it is important for care providers to show that they are willing to talk with the patients about these difficult matters.

\section{Societal perspective}

From a societal perspective, it is important to attract attention to these matters. The existential questions and thoughts which the patient may have and which he or she in many instances cannot or does not express, can lead to psychical problems. Unexpressed concerns may also aggravate the patient's original physical problems, which may increase their need for further medical care.

\section{Research perspective}

Many studies examining life style changes concern voluntary choices. For example, some studies include healthy people for whom lifestyle changes lead to favourable physical consequences, examining physical, medical and economical aspects of the change (8-11). Other studies examine the existential and ethical aspects of lifestyle changes necessitated by diseases (12-17), including how nurses can be involved in these lifestyle changes (18). Although these constitute a promising beginning, Løgstrup's concepts could represent a useful framework for further studies. From both a patient and a societal perspective, such clinical studies would be useful to provide a better understanding of the patient experience and to help improve the application of this understanding in a clinical setting.

\section{Conclusion}

Persons who involuntarily or voluntarily are faced with need for change in lifestyles often experience a crisis reaction that causes them to ask questions about life itself. This does not seem to have been sufficiently addressed by the health care sector. If the person does not receive psychological support, the effects of the crisis reaction may be intensified. Also, the person may then begin to wonder whether there is a meaning of life.

To promote not only the physical but also the mental health of those undergoing lifestyle changes it is important to look at the patient as a whole. K.E. Løgstrup's philosophy of the basic conditions of life provides a useful framework for considering how healthcare providers can better consider patients in their entirety, rather than viewing them as objects that consist of organs to be treated. Health care providers should be sensitive to the existential questions that can arise from significant lifestyle changes, so that they can better listen and respond to these questions.

\section{Competing Interests}

None declared.

\section{References}

(1) Løgstrup KE. Beyond the ethical demand. Notre Dame: University of Notre Dame: Press; 2007.

(2) Sachs L. [IIlness as a disorder: the human being at the border between good health and disease.] In Swedish. Stockholm: Natur och Kultur; 2012.

(3) Dondorp W, de Wert G, Pennings G, Shenfield F, Devroey P, Tarlatzis B, Barri P. Lifestyle-related factors and access to medically assisted reproduction. Human Reproduction 2010; 3:578-83.

(4) Arlebrink J, Larsson Kronberg M. (eds.). Tvångsvård vid missbruk. [Coercive treatment at alcohol misuse] Lund: Studentlitteratur; 2005.

(5) Arlebrink J. [The moral question and the existential suffering - how an alcohol abuser experiences compulsory treatment] In Swedish. Lund: Lund University; 2004.

(6) Frankl V. Man's Search for Meaning. The Classic Tribute to Hope from the Holocaust. London: Rider \& Co; 2004.

(7) Holm U. [Being kind is not enough, about empathy and professional approach in carring professions] In Swedish. Stockholm: Natur och Kultur; 2009.

(8)Knutsen IR, Terragni L, Foss C. Morbidly obese patients and lifestyle change: constructing ethical selves. Nursing Inquiry 2011; 4:348-58.

(9) Walseth LT, Abildsnes E, Schei E. Lifestyle, health and ethics of good living. Health behavior counselling in general practice. Patient Educ Couns; 2011; 2:180-4.

(10) Vandereycken W. Self-Change in Eating Disorders: Is "Spontaneous Recovery" Possible? Eating Disorders: The Journal of Treatment \& Prevention 2012; 20:87-98.

(11) Sjögren K. (2013): Participation in physical activity in relation to different life-change events. Lund: Lund University, Department of clinical sciences in Malmö.

(12) Landmark BT, Wahl A. Living with newly diagnosed breast cancer: a qualitative study of 10 women with newly diagnosed breast cancer. J Adv Nurs 2002; 1:112-21.

(13) Patterson RE, Neuhouser ML, Hedderson MM, Schwartz SM, Standish LJ, Bowen, DJ. Changes in diet, physical activity, and supplement use among adults diagnosed with cancer. J Am Diet Assoc 2003; 3:323-8.

(14) Cotton S, Tsevat J, Szaflarski M, Kudel I, Sherman SN, Feinberg J, Leonard AC, Holmes WC. Changes in religiousness and spirituality attributed to HIV/AIDS: are there sex and race differences? J Gen Intern Med 2006; Suppl 5:14-20.

(15) Westin L. Nilstun T. Principles help to analyse but often give no solution - secondary prevention after a cardiac event. Health Care Anal 2006; 2:111-7. (16) Kostopoulou V, Katsouyanni K. The truth-telling issue and changes in lifestyle in patients with cancer. J Med Ethics 2006; 12:693-7.

(17) Caocci G, La Nasa G, d'Aloja E, Vacca A, Piras E, Pintor M, Demontis R, Pisu S. Ethical issues of unrelated hematpopoietic sten cell transplantation in adult thalassemia patients. BMC Medical Ethics 2011; $12: 4$.

(18) Naef R. Bearing witness: a moral way of engaging in the nurse-person relationship. Nurse Philos 2006; 3:146-56. 